\title{
Treatment of Paget's disease of bone with single dose intravenous pamidronate
}

\author{
R A Watts, S J Skingle, M M Bhambhani, G Pountain, A J Crisp
}

\begin{abstract}
Objectives-To assess the efficacy of a single intravenous infusion of pamidronate in Paget's disease of bone.

Methods-Fourteen patients with active Paget's disease (raised serum alkaline phosphatase, bone pain or neurological involvement) were treated with a single intravenous infusion of $105 \mathrm{mg}$ pamidronate. Patients were assessed for biochemical and clinical improvement for up to two years following treatment. A further infusion was given following symptomatic relapse (pain at a known site of pagetic involvement).

Results-Serum alkaline phosphatase fell following treatment, with a nadir 5.9 months after treatment. Bone pain was improved in nine of 12 patients after six months. Retreatment of four patients resulted in a similar response.

Conclusion-Single dose intravenous pamidronate $(105 \mathrm{mg})$ is a convenient and effective treatment for Paget's disease.
\end{abstract}

(Ann Rheum Dis 1993; 52: 616-618)

Bisphosphonates are effective in the treatment of conditions such as Paget's disease in which there is increased bone resorption. Animal studies indicate that the second generation bisphosphonate pamidronate (3-aminohydroxypropylidene-1,1-bisphosphonate) is more potent than clodronate or etidronate. ${ }^{1} \mathrm{~A}$ variety of oral and intravenous regimens have been used in the treatment of Paget's disease with pamidronate. ${ }^{2-13}$ Treatment by mouth is limited because of gastrointestinal intolerance and poor absorption, making the intravenous route preferable. ${ }^{4}$ Most previous studies of intravenous pamidronate used either a daily or weekly dosing schedule resulting in biochemical improvement for up to one year. ${ }^{3-10}$ Single dose $(60 \mathrm{mg})$ intravenous treatment is effective, with suppression of alkaline phosphatase to approximately one third of pretreatment values for one year. ${ }^{2}$ We now report our experience of intravenous single high dose (105 mg) treatment.

\section{Patients and methods}

Fourteen patients with Paget's disease were studied (table 1). Patients were included if they had bone pain, or neurological impairment attributable to Paget's disease, and a serum alkaline phosphatase greater than the upper limit of normal (135 U//). Pretreatment assessment included: clinical examination, radionuclide scintigraphy $\left({ }^{99 \mathrm{~m}} \mathrm{Tc}\right.$ methylene bisphosphonate) with measurement of 24 hour whole body retention of bisphosphonate (normal value less than $40 \%$ ) and radiography of affected bones, full blood count, serum calcium (corrected for serum albumin; $2 \cdot 0-2 \cdot 4$ $\mathrm{mmol} / \mathrm{l})$, phosphate $(0 \cdot 8-1.4 \mathrm{mmol} / \mathrm{l})$, alanine transaminase (7-40 U/1), alkaline phosphatase (30-135 U/1), and albumin. A 24 hour urine collection was obtained to assess the hydroxyproline/creatinine ratio $(0.006-0.030)$.

Pamidronate was given as a single infusion of $105 \mathrm{mg}$ in 1 litre of $5 \%$ dextrose over 24 hours. Four patients received a second infusion and a single patient a third infusion because of symptomatic relapse, defined as pain at a previously documented site of pagetic involvement. Similar assessments excluding bone scintigraphy were performed at one, two, and three months after treatment, and at threemonthly intervals thereafter. Pain was assessed subjectively as either worse, unchanged, or better.

Statistical analysis was performed using Wilcoxon's rank sum test to compare values before and after treatment.

\section{Results}

Table 1 lists the clinical features of the patients. All 14 patients had active Paget's disease with raised alkaline phosphatase levels. Whole body retention of bisphosphonate was increased in 10 patients. Polyostotic disease was present in 13. Nine had received previous treatment. Two patients had minor increase of alanine transaminase levels (less than 1.5 times the upper limit of normal).

Bone pain was present in 12 patients before treatment and was improved in nine patients after six months. In two patients the pain was worse at this time, but had improved after three months.

Table 2 shows the effect of the first infusion of pamidronate on mean values of alkaline phosphatase, calcium, phosphate, and the hydroxyproline/creatinine ratio. The lowest level of alkaline phosphatase occurred 5.9 months (2-9 months) after treatment (figure). It fell to within the normal range in 10 patients (mean 2.4 months). In those patients in whom normalisation did not occur, in three out of four, the initial value was less than $500 \mathrm{U} / 1$. There was a transient, asymptomatic fall in the corrected serum calcium maximum one month (2.14 (SEM 0.03) $\mathrm{mmol} / \mathrm{l}, \mathrm{p}=0.0022)$ after treatment. By three months, calcium levels had returned to pretreatment values. There was no 
Table 1 Clinical features of patients treated with single dose pamidronate

\begin{tabular}{lllllllll}
\hline Patient & $\begin{array}{l}\text { Age } \\
\text { (years) }\end{array}$ & Sex & $\begin{array}{l}\text { Disease } \\
\text { duration } \\
\text { (years) }\end{array}$ & $\begin{array}{l}\text { Previous } \\
\text { treatment }\end{array}$ & Clinical features & $\begin{array}{c}s A P \\
(U /) \dagger\end{array}$ & $\begin{array}{l}s A P \\
(U /) \ddagger\end{array}$ & $\begin{array}{l}W B R \\
(\%) \ddagger\end{array}$ \\
\hline 1 & 64 & F & 15 & C,E,Pi & Pain, deaf & ND & 630 & 57 \\
2 & 76 & F & 23 & C & Pain & 464 & 522 & 65 \\
3 & 82 & M & 10 & C & Pain, deaf & ND & 525 & 74 \\
4 & 65 & F & $<1$ & None & Vestibular dizziness & 303 & 303 & ND \\
5 & 71 & F & 10 & Co,E,Pi,A & Pain & 384 & 197 & 46 \\
6 & 70 & F & 14 & None & Pain & 287 & 287 & 44 \\
7 & 69 & M & ND & None & Deaf, tinnitus & ND & 283 & ND \\
8 & 59 & M & 1 & C & Pain & 222 & 204 & ND \\
9 & 78 & M & 1 & C,E & Pain & 581 & 742 & 77 \\
10 & 57 & M & 10 & Co,P,E & Pain & 472 & 371 & 67 \\
11 & 78 & F & 2 & C,E & Pain & 337 & 487 & 57 \\
12 & 70 & F & 7 & None & Pain, leg paraesthesiae & 209 & 209 & 47 \\
13 & 76 & M & $<1$ & None & Pain & ND & 348 & ND \\
14 & 59 & F & 20 & E & Pain, deaf & ND & 643 & 58 \\
\hline
\end{tabular}

^Known disease duration from diagnosis to first course of pamidronate. tValues before any specific antipagetic treatment.

$\mathrm{C}=$ =alcitonin; $\mathrm{E}=$ =etidronate; $\mathrm{Pi}=$ plicamycin; $\mathrm{Co}=$ Colchicine; $\mathrm{A}=$ pamidronate; $\mathrm{P}=$ prednisolone; $\mathrm{C}=$ calcitonin; $\mathrm{E}=$ etidronate; $\mathrm{Pi}=$ plicamycin; $\mathrm{Co}=$ Colchicine; $\mathrm{A}=$ pamidronate; $\mathrm{P}=$ prednisolone;
$\mathrm{ND}=$ no data; $\mathrm{sAP}=$ serum alkaline phosphatase $(35-135 \mathrm{U} / \mathrm{l}) ; \mathrm{WBR}=$ whole body retention ND=no data; sAP=serum
bisphosphonate $(<40 \%)$.

Table 2 Biochemical response to first pamidronate infusion

\begin{tabular}{lccc}
\hline & Pretreatment & After 3 months & After 6 months \\
\hline Alkaline phosphatase (U//) & $411 \pm 48$ & $163 \pm 32^{\star}$ & $141 \pm 34^{\star}$ \\
Corrected calcium (mmol/) & $2 \cdot 29 \pm 0 \cdot 02$ & $2 \cdot 26 \pm 0 \cdot 04$ & $2 \cdot 23 \pm 0 \cdot 03$ \\
Phosphate (mmol/l) & $1 \cdot 04 \pm 0 \cdot 03$ & $1 \cdot 05 \pm 0 \cdot 03$ & $1 \cdot 05 \pm 0 \cdot 03$ \\
Hydroxyproline/creatinine ratio & $0 \cdot 0419 \pm 0 \cdot 0071$ & $0 \cdot 029 \pm 0 \cdot 0420$ & $0 \cdot 0193 \pm 0 \cdot 0054^{\star \star}$ \\
\hline
\end{tabular}

${ }^{\star} \mathrm{p}<0.005 ;{ }^{\star \star} \mathrm{p}<0.05$.

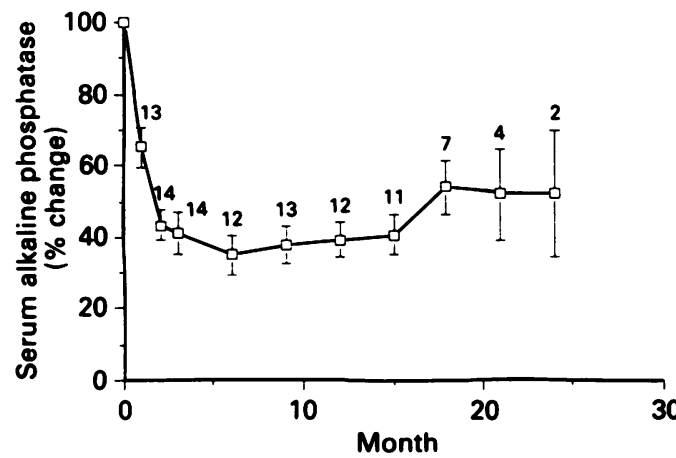

Change in serum alkaline phosphatase from baseline value (mean(SEM)) following first infusion of pamidronate. Numbers at each time point represent number of patients assessed.

significant effect on serum phosphate levels. In five patients in whom complete data were available there was a significant fall in 24 hour urinary hydroxyproline/creatinine ratios.

Four patients received a second infusion at a mean interval of 18.75 months (15-24 months) after the initial dose. This resulted in a similar clinical and biochemical response to the first course with improvement in bone pain and a fall in alkaline phosphatase, which fell from $310(101) \mathrm{U} / 1$ to $171(70) \mathrm{U} / \mathrm{l}$ after six months. The hydroxyproline/creatinine ratio fell from $0.0450(0.0084)$ to $0.0205(0.0088)$ after six months. One patient received a third course 24 months after the second infusion, again with an improvement in symptoms.

One patient died of cranial osteosarcoma three months after treatment, having had a good initial response. A second patient was treated. with plicamycin 10 months after receiving pamidronate. The remaining eight patients have had symptomatic improvement for up to 21 months (mean $16 \cdot 1$ months).
The infusions were well tolerated in most patients. A transient pyrexia (up to $39^{\circ} \mathrm{C}$ ) was observed 24-48 hours after treatment in four. No significant haematological effects were seen.

\section{Discussion}

In this study we have shown that a single infusion of $105 \mathrm{mg}$ pamidronate can produce prolonged (up to 21 months) clinical and biochemical improvement in Paget's disease. The optimum therapeutic regimen is controversial. Short courses of daily or weekly treatment result in significant suppression of alkaline phosphatase that is still present one year after treatment, ${ }^{5-8}$ whereas Thiebaud used a single infusion of $60 \mathrm{mg}$ with reduction of alkaline phosphatase and urinary hydroxyproline excretion for up to 12 months. ${ }^{2}$ Direct comparison between studies is difficult because of the variation in disease severity. Our patients had relatively mild disease with mean alkaline phosphatase levels three times the upper limit of normal. The data compare favourably with results of other studies. We achieved normalisation of alkaline phosphatase in $10 / 14$ patients $(71.4 \%)$ after the first infusion, a figure comparable with other studies. $^{5-8}$ However, three out of four patients in whom normalisation of alkaline phosphatase did not occur, had pretreatment levels under $500 \mathrm{U} / 1$ suggesting that higher doses may be required for more severely affected patients. Such a dose-response phenomenon was observed by Gallacher, who suggested that, in more severely affected patients with more active pagetic lesions, the drug was spread more widely and hence the effective dose at each site was lower. ${ }^{3}$ The lowest alkaline phosphase level was 5.9 months after treatment, and thereafter there was a gradual increase, suggesting that longlasting biochemical suppression of disease was achieved. In four patients second infusions were given, again with improvement. The fall in alkaline phosphatase was not statistically significant, because only four patients were treated. Although the data are incomplete, we have shown a fall in the urinary hydroxyproline/creatinine ratio following treatment, an observation confirmed by other studies. $^{2} 361213$

Assessment of bone pain in Paget's disease is difficult, because there may be a major contribution from other causes, such as coexistent osteoarthritis. Subjective assessment with a simple three point score (better, unchanged, worse) suggests that pamidronate produces an improvement in pain for at least six months.

We conclude that this treatment was well tolerated and is a simpler and more convenient regimen than those previously described Further studies are required to define the optimum dose for single infusion therapy and to compare this regimen with a conventional six month course of oral etidronate. We also need to determine how rapidly pamidronate $105 \mathrm{mg}$ can be infused safely. If effective treatment can be given at a single outpatient visit then the cost implications are significant. 
1 Shinoda H, Adamek G, Felix R, Fleisch H, Schenk R, Hagen P. Structure activity relationship of various bisphosphonates. Calcif Tissue Int 1983; 35: 87-93.

2 Thiebaud D, Jaeger P, Gobelet C, Jacquet A F, Burckhardt P. A single infusion of the bisphosphonate AHPrBP (APD) as a treatment of Paget's disease of bone. $A m \mathfrak{F}$ Med 1988; 85: 207-12

3 Gallacher S J, Boyce B F, Patel U, Ralston S H, Boyle I T. Clinical experience with pamidronate in the treatment of Paget's disease of bone. Ann Rheum Dis 1991; 50: $930-3$.

4 Fogelman I, Smith L, Mazess R, Wilson M A, Bevan J A. Absorption of oral diphosphonates in normal subjects. Clin Endocrinol (Oxf) 1986; 24: 57-62.

5 Cantrill J A, Buckler H M, Anderson D C. Low dose intravenous 3-aminohydroxypropylidene-1,1-bisphosphonate (APD) for the treatment of Paget's disease of bone. Ann Rheum Dis 1986; 45: 1012-8.

6 Harinck H I J, Papapolous S E, Blanksma H J, Moolenaar A J, Vermeij P, Bijvoet O L M. Paget's disease of bone: early and late responses to three different modes of treatment with aminohydroxypropylidene-1,1-bisphosphonate (APD). BMF 1987; 295: 1301-5.

7 Ryan P J, Sherry M, Gibson T, Fogelman I. Treatment of Paget's disease by weekly infusion of 3-aminohydroxy- propylidene-1,1-bisphosphonate (APD). $B r \mathcal{F}$ Rheumatol 1992; 31: 97-101.

8 Fenton A J, Gutteridge D H, Kent G N, et al. Intravenous aminobisphosphonate in Paget's disease: clinical biochemical, histomorphometric and radiological responses. Clin Endocrinol (Oxf) 1991; 34: 197-204.

9 O'Doherty D P, Bickerstaff D R, McCloskey E V, et al. Treatment of Paget's disease of bone with aminohydroxybutylidene bisphosphonate. $\mathcal{F}$ Bone Min Res 1990; 5: 483-91.

10 Thiebaud D, Jaeger P, Burckhardt P. Paget's disease of bone treated in 5 days with AHPrBP (APD) per os. $\mathcal{F}$ Bone Miner Res 1987; 2: 45-52.

11 Fraser T R, Ibbertson H K, Holdaway I M, et al. Effective oral treatment of severe Paget's disease with APD (3-aminohydroxypropylidene-1,1-bisphosphonate); comparison with combined calcitonin and EHDP (1-hydroxyethylidene-1,1-bisphosphonate). Aust $N Z \mathcal{F}$ Med 1984; 14: 811-8.

12 Mautalen C A, Gonzalez D, Ghinnghelli G. Efficacy of the bisphosphonate APD in the control of Paget's bone disease. Bone 1985; 6: 29-32.

13 Vega E, Gonzalez D, Ghinnghelli G, Mautalen C. Intravenous aminopropylidene bisphosphonate in the treatment of Paget's bone disease. F Bone Miner Res 1987; 2: 267-71.

$\frac{2}{3}$ 